\title{
Efficiency Evaluation Study about the New and the Old Circulation Modes of Agricultural Products of Fruits and Vegetables in Beijing*
}

\author{
Xiuli Tang, Rui Wang, Fangwen Yang, Lixiang Huang \\ Beijing Wuzi University, Beijing, China \\ Email:m18842667735@163.com
}

How to cite this paper: Tang, X.L., Wang, R., Yang, F.W. and Huang, L.X. (2016) Efficiency Evaluation Study about the New and the Old Circulation Modes of Agricultural Products of Fruits and Vegetables in Beijing. Modern Economy, 7, 1050-1060. http://dx.doi.org/10.4236/me.2016.710107

Received: August 4, 2016

Accepted: September 4, 2016

Published: September 7, 2016

Copyright $\odot 2016$ by authors and Scientific Research Publishing Inc. This work is licensed under the Creative Commons Attribution International License (CC BY 4.0).

http://creativecommons.org/licenses/by/4.0/

\begin{abstract}
Firstly, there is a brief introduction about the new and the old circulation modes of Agricultural Products of fruits and vegetables in Beijing. And there will be an empirical analysis about it by constructing DEA model. The conclusion is that efficiency of the new circulation mode is higher than the old one. And the new mode can compensate for the low efficiency of the old model circulation deficiencies and improve the efficiency of agricultural products circulation of fruits and vegetables in Beijing.
\end{abstract}

\section{Keywords}

Circulation Mode, DEA Model, Efficiency Evaluation

\section{Introduction}

With the advancement of the process of Integration of Beijing-Tianjin-Hebei regions, the non-functional core industries of Beijing will move away gradually. So circulation efficiency will become a decisive factor in agricultural products to meet the demand of fruits and vegetables in Beijing. Although currently the circulation system of Beijing has formed a certain scale, but there are still many problems in circulation mode such as information technology of circulation is immature, the level of the logistics technology is low and the quality and safety of agricultural products are difficult to guarantee. In addition, with the increasing demand of consumers, it is the most important issue for development of agricultural products logistics to build a new mode of efficient circulation of agricultural products and it also will change some backward states to meet consumers' demand [1].

${ }^{*}$ Project fund support: The work was supported by Beijing Nova Program (Z121106002512043); The General Social Science Program of Beijing Municipal Education Commission (SM201310037001); Philosophical and Social Science Program (12JGC107). 
For now, circulation models of agricultural products in Beijing mainly include wholesale market oriented mode, mode with supermarket as core, mode with logistics centre as main body, mode with leading enterprise as core, agricultural products direct selling, electronic commerce, etc. But Beijing's agriculture products circulation has a bad organized system, with many and diverse processes and inefficiency in many aspects, so it increases the cost of the self-employed in the transaction process to cause high prices of agricultural products and farmers cannot share the benefit brought by the rising agricultural product price; in agricultural product logistics, the waste is in a high-level and the efficiency is very low; the agricultural product supply chain has not yet been formed because of the lack of circulation main body with the feature of supply chain core enterprises [2].

Therefore, this paper proposes a new circulation mode that is re-integration of land resources and social resources in the perspective of the whole industry chain. The existing mode is circulation organizers and producers of large scale plant fruits and vegetables by renting or buying land. And the new circulation mode is powerful circulation organizers as procurement centers which are dominant power to control the flow of agricultural products and to regulate resources and circulation channels of agricultural products.

\section{The New and the Old Circulation Modes of Agricultural Products of Fruits and Vegetables in Beijing}

The old circulation mode of agricultural products of fruits and vegetables is same as the existing mode mentioned in the above. The new circulation mode share and reuse of existing land resources and product resources in the perspective of the whole industry chain.

\subsection{The Old Circulation Modes of Fruits and Vegetables in Beijing}

\subsubsection{The Wholesale Markets as the Leading Circulation Mode}

The circulation mode of fruits and vegetables, is dominated by the wholesale markets, is the main flow pattern of Beijing at present. The wholesale markets have a strong distribution function, but they have no ability to directly face the huge number of producers and buyers of fruits and vegetables, so it can not only exist the wholesale market in the circulation processes that other main bodies of circulation will certainly join in [3]. The diagram of the model is shown in Figure 1.

\subsubsection{The Circulation Modes of Fruits and Vegetables from Farm to Market}

This mode is based on direct procurement between powerful supermarkets and agricultural producers of fruits and vegetables through contracts. In other words, supermarkets have their own direct mining bases that reduce the circulation of links and improve the efficiency of logistics fundamentally. However, this model also has difficulties to implement: 1) Loose, small mode of production led to the difficulty of direct procurement. 2) Lack of technical guidance of crop specifications, quality and so cannot be guaranteed. 3) Traditional ways of capital settlement affect docking efficiency [4]. The 


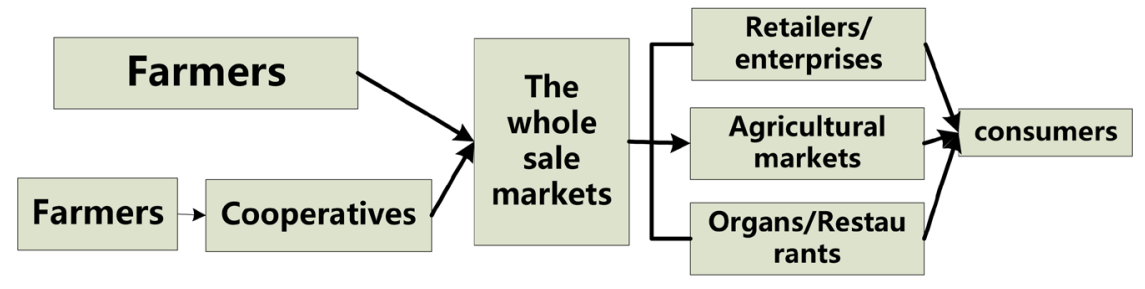

Figure 1. The wholesale markets as the leading circulation mode.

diagram of the model is shown in Figure 2.

\subsubsection{Logistics Center as the Main Circulation Mode}

With the continuous development of science and technology and the acceleration of the market process, the types of agricultural products, production and processing and consumption are also becoming increasingly diverse. The background of this circulation mode is some sharp carriers want to develop logistics company by integrating resources. And the logistics company will be an integrated logistics center to achieve fast and efficient distribution of agricultural products. The model is connected to the producer and terminal retailers, so it reduces the wholesale segments to improve the circulation efficiency of agricultural products, ensure freshness of agricultural products and reduce the logistics cost [5]. The diagram of the model is shown in Figure 3.

\subsubsection{Leading Enterprises as the Dominant Circulation Mode}

Agricultural producers and leading enterprises signed a contract and leading enterprises will buy agricultural products with slightly higher price than the market under this mode. Besides, leading enterprises will provide farmers with the information of products and technical guidance then farmers will produce and harvest in accordance with the standards set by the leading enterprises. That will reduce farmers' risk, because farmers and leading enterprises which have the ability to control the information and bear a strong risk have signed a contract. But leading enterprises as buyer still stand in advantage, the benefits of farmers cannot be fully guaranteed [6]. The diagram of the model is shown in Figure 4.

\subsection{The New Circulation Modes of Fruits and Vegetables in Beijing}

The new circulation mode is the innovation of the circulation mode of the fruits and vegetables in Beijing from the perspective of the whole industry chain. Specifically, it controls resources of agricultural products as the core by the global ideological guidance, controls the planting by a core enterprise, controls its sales by downstream in the supply train, controls the circulation of the entire process. Through the whole industry chain resources' integration and information sharing, the quality and safety of agricultural products will be guaranteed, the circulation efficiency will improve and the prices of agricultural products will be stabilize.

The new circulation mode share and reuse of existing land resources and product resources in the perspective of the whole industry chain. The aim of reusing existing land resources is to realize the innovate circulation of "organizers + producer" mode 


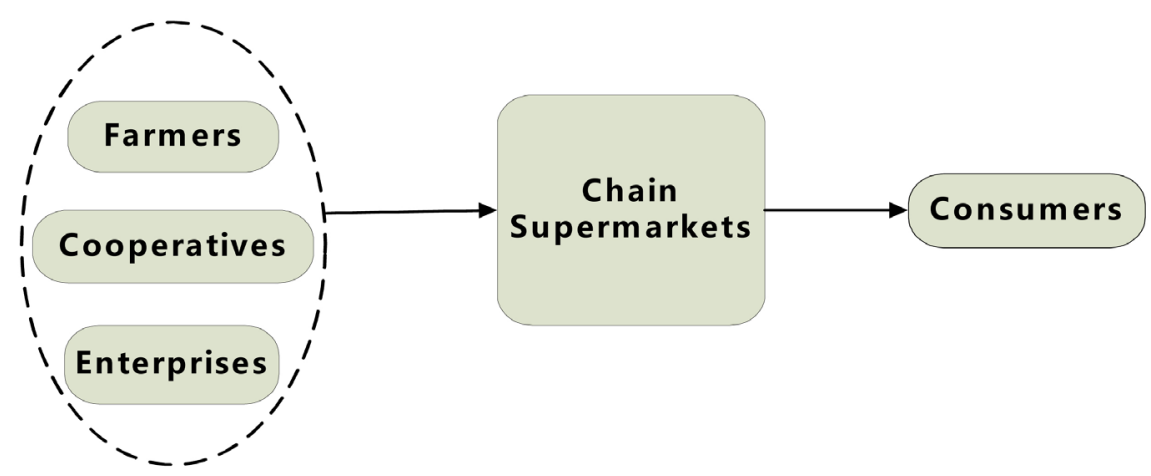

Figure 2. The circulation modes of fruits and vegetables from farm to market.

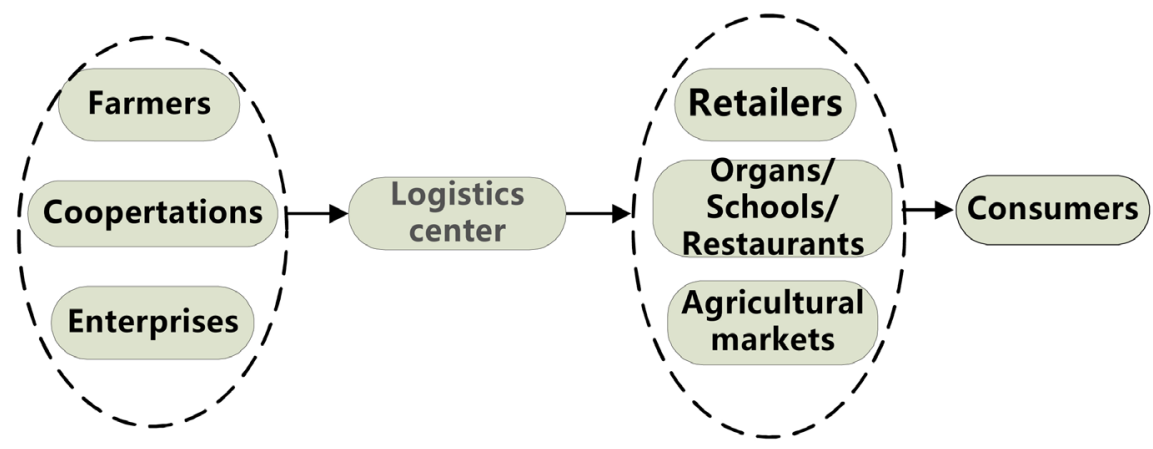

Figure 3. Logistics center as the main circulation mode.

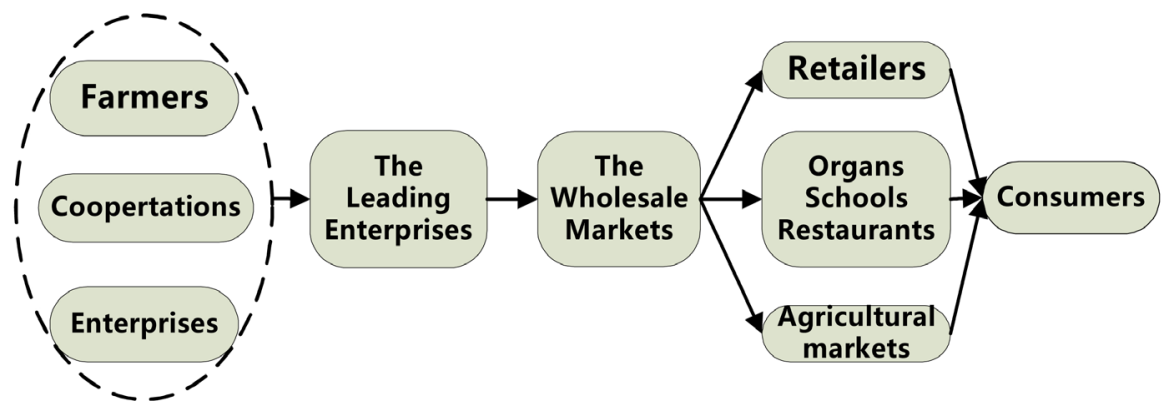

Figure 4. Leading enterprises as the dominant circulation mode.

and the scale of the fruit and vegetable agricultural production by renting or buying land. The diagram of the model is shown in Figure 5. The aim of reusing existing product resources is to control the circulation of agricultural products by changing the powerful organizers into the procurement center. The diagram of the model is shown in Figure 6.

\section{Efficiency Evaluation about the New and the Old Circulation Modes of Agricultural Products of Fruits and Vegetables}

Beijing existing several circulation modes mentioned above and the new circulation modes based on the whole industry chain were compared to empirical analysis to get the highest efficiency of circulation mode by establishing DEA evaluation model and 


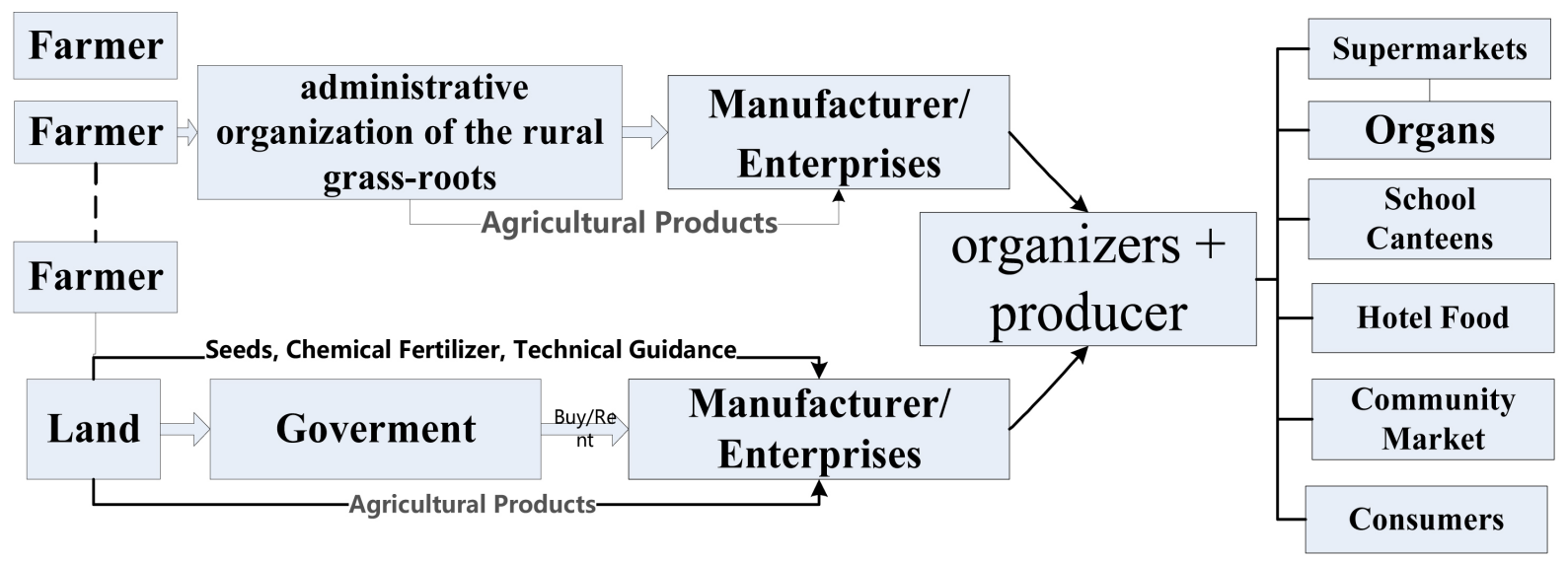

Figure 5. The innovative circulation of "organizers + producer" mode.

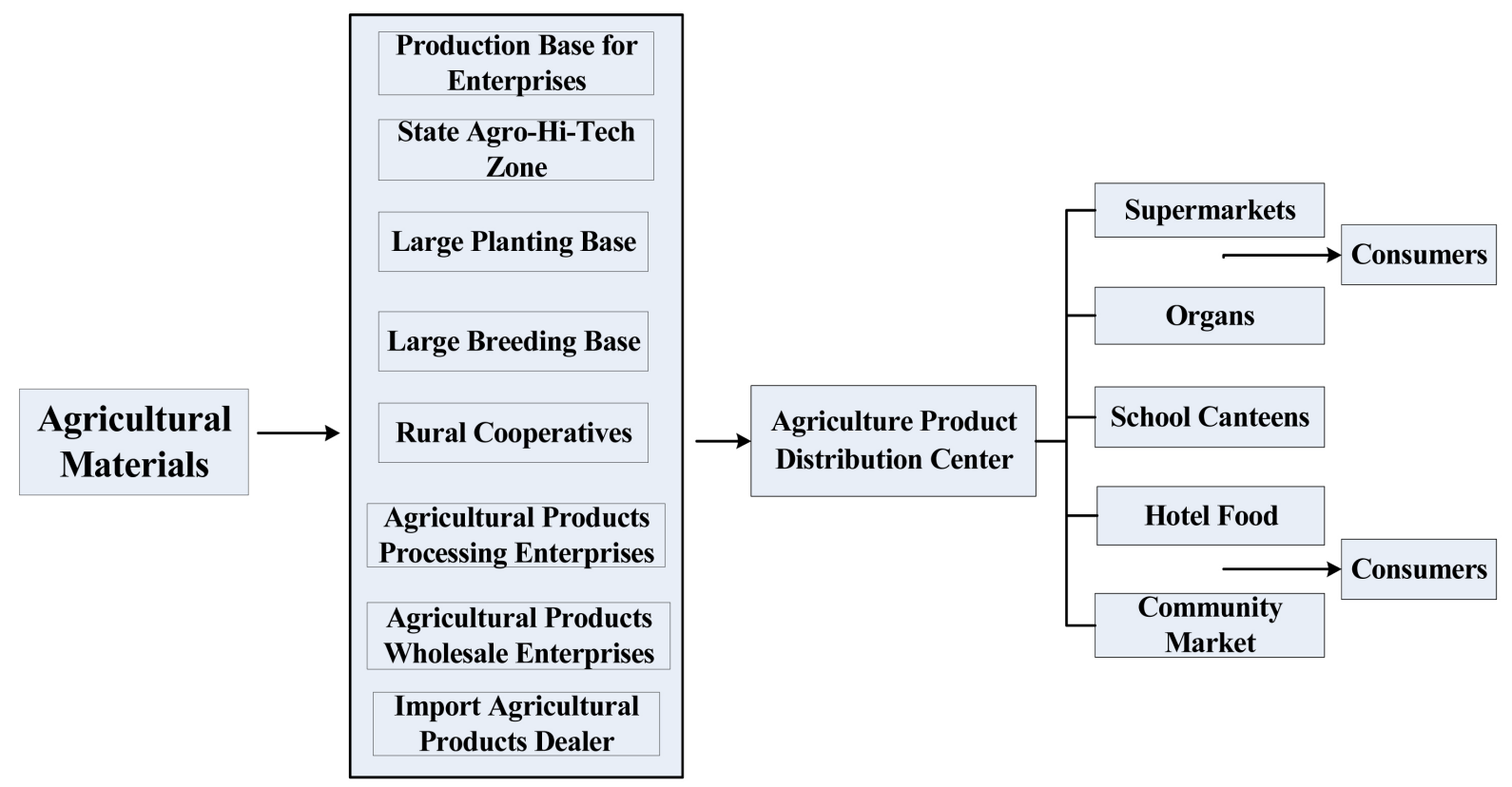

Figure 6. The innovative circulation of changing the powerful organizers into the procurement center.

index system.

\subsection{Set-Up of DEA Evaluation Model}

\subsubsection{Setting Evaluation Indexes}

According to the research setting evaluation indexes, science and objectivity cannot be fully guaranteed, so that the evaluation results will be affected accordingly. So the setting of index is very important especially in the case of a wide range of factors in the process of circulation of agricultural products. DEA is an analytical method commonly used in the evaluation of efficiency and productivity. It is not necessary to quantify the comprehensive input and output and determine the mathematical relationship expression between variables and determine the weight in advance. Only through the input and output data, it can effectively handle multiple input and multiple output indicators 
evaluation.

\subsubsection{Construction of $\mathrm{C}^{2} \mathrm{R}$ Model}

Setting $V_{i}$ as the weight of the $i$-th index of $X_{i}, u_{r}$ as the weight of the $r$-th output index of $y_{r}$, so the $j$-th circulation patterns into integrated value is $\sum_{i=1}^{3} v_{i} x_{i j}$, the comprehensive value of output is $\sum_{r=1}^{2} u_{r} y_{r j} \quad$ [7]. Its production efficiency is defined as

$$
h_{j}=\frac{\sum_{i=1}^{3} v_{i} x_{i j}}{\sum_{r=1}^{2} u_{r} y_{r j}} .
$$

So the problem is actually to determine a group of the right variables $V_{1}, V_{2}, V_{3}$ and $U_{1}, U_{2}$, so that the efficiency of the $j$-th circulation enterprise how to make efficiency value $h_{j}$ maximum value. The maximum value is the value that is not likely to be higher to the other modes. Limiting all $h_{j}$ values $(j=1,2,3)$ to no more than $1, \max h_{j} \leq 1$. That is to say, to determine whether a DMU is valid need to see whether the $h_{k}$ is 1 . If $h_{k}=1$, the circulation system in the circulation mode is relatively effective. If $h_{k}<1$, the circulation system in the circulation mode is not relatively effective. According to the above analysis, it can be established to determine the relative productivity optimization model of any enterprise is as follows:

$$
\begin{aligned}
& \max H=h_{3} \\
& \text { s.t. }\left\{\begin{array}{ll}
h_{j} \leq 1, & j=1,2,3 \\
u_{r} \geq 0, & r=1,2 \\
v_{i} \geq 0, & i=1,2,3
\end{array} .\right.
\end{aligned}
$$

\subsubsection{Evaluating DMUs and Building the Efficiency Model}

Formally, consider $\mathrm{n}$ circulation enterprises or DMUs that are to be evaluated, all using the same $\mathrm{m}$ inputs to produce $\mathrm{p}$ different outputs. The following table shows the input and output relations of these circulation enterprises (Table 1).

The efficiency evaluation index of each DMU is defined as:

$$
h_{j}=\frac{\sum_{r=1}^{p} u_{r} Y}{\sum_{i=1}^{m} v_{i} X} .
$$

The mode of relative efficiency optimization evaluation of the $j_{0}$-th decision making unit is:

$$
\max h_{j 0}=\frac{\sum_{r=1}^{p} u_{r} Y}{\sum_{i=1}^{m} v_{i} X},
$$


Table 1. To represent the input and output relations of these circulation enterprises.

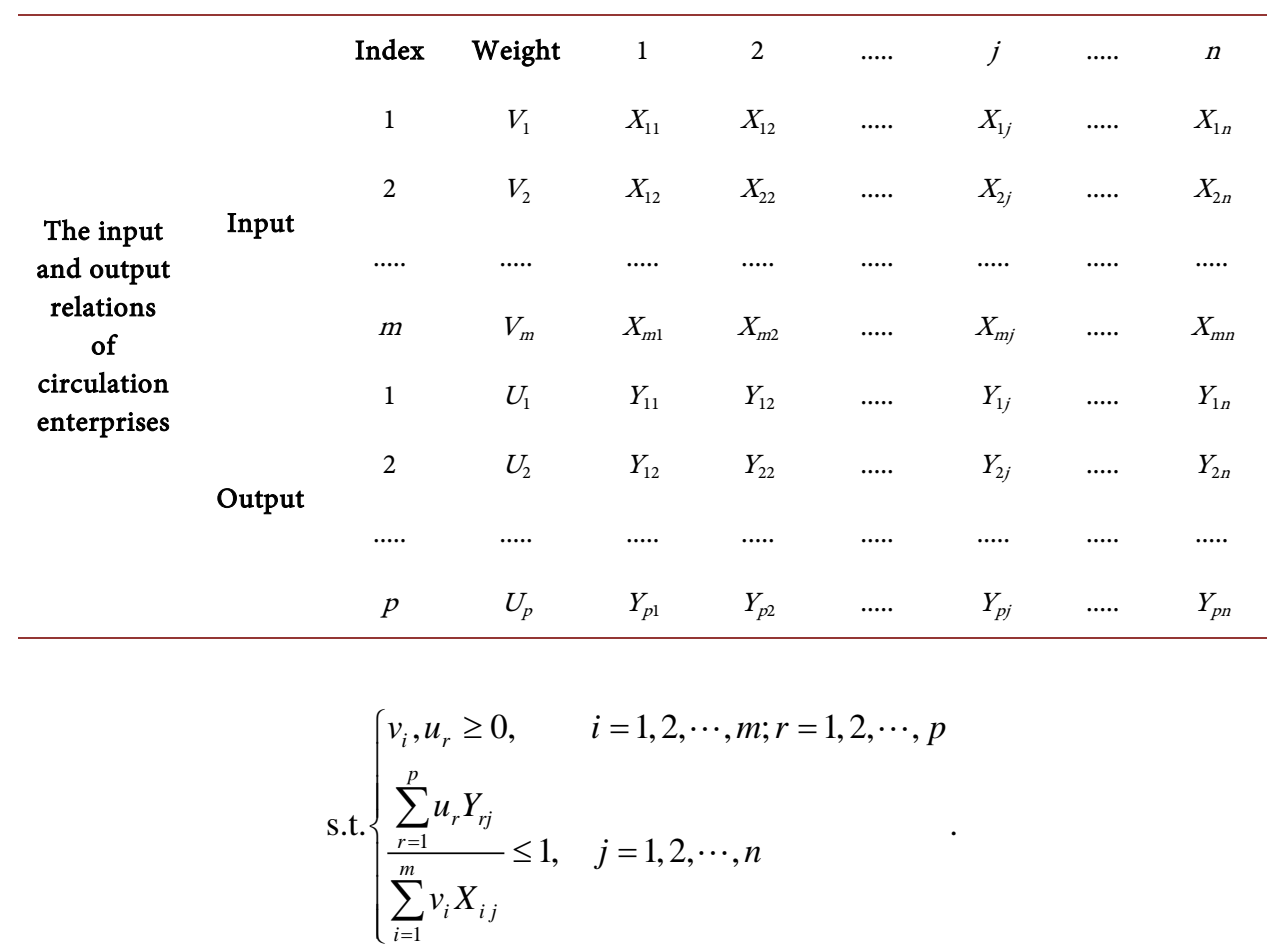

In the above model, $X_{i j}, Y_{r j}$ are known, $v_{P}, u_{r}$ are variable. The model definition are weight coefficient $v_{p}, u_{r}$ as variable, all efficiency indicator $h_{j}$ of DMUs as constraint, the efficiency index of the $j_{0}$-th DMU as the goal. Whether the circulation efficiency of the $j_{0}$-th DMU is effective over other DMUs, this is a fractional programming model, which must be changed into a linear programming model to solve the problems. Making $\mu_{r}=$ $t u_{r}, \omega_{i}=t v_{p}$ the above model is translated into:

$$
\begin{gathered}
\max h_{j o}=\sum_{r=1}^{p} u_{r} Y_{i j 0} \\
\text { s.t. } \begin{cases}\sum_{r=1}^{p} u_{r} Y_{r j}-\sum_{i=1}^{m} w_{i} X_{i j} \leq 0, & j=1,2, \cdots, n \\
\sum_{i=1}^{m} w_{i} X_{i j 0}=1, & j=1,2, \cdots, n . \\
u_{r}, w_{i} \geq 0, i=1,2, \cdots, m ; & r=1,2, \cdots, p\end{cases}
\end{gathered}
$$

Written in vector form as:

$$
\begin{gathered}
\max h_{j 0}=\mu^{\mathrm{T}} Y_{0} \\
\text { s.t. }\left\{\begin{array}{l}
\mu^{\mathrm{T}} Y_{j}-w^{\mathrm{T}} X_{j} \leq 0 \\
w^{\mathrm{T}} X_{0}=1 \\
w \geq 0, \mu \geq 0
\end{array} \quad j=1,2, \cdots, n .\right.
\end{gathered}
$$

The dual problem is:

$$
\max V_{D}=\theta
$$




$$
\text { s.t. }\left\{\begin{array}{ll}
\sum_{j=1}^{n} \lambda_{j} X_{i j} \leq \theta X_{i 0}, & i=1,2, \cdots, m \\
\sum_{j=1}^{n} \lambda_{j} Y_{r 0}, & r=1,2, \cdots, p \\
\lambda_{j} \geq 0, & \theta \text { is unconstraint conditions }
\end{array} .\right.
$$

Written in vector mode:

$\min \theta$

$$
\text { s.t. }\left\{\begin{array}{l}
\sum_{j=1}^{n} \lambda_{j} x_{j}+S^{-}=\theta X_{0} \\
\sum_{j=1}^{n} \lambda_{j} y_{j}-S^{+}=Y_{0} \\
S^{-} \geq 0, S^{+} \geq 0, \lambda_{j} \geq 0 \\
\theta \text { is unconstraint conditions }
\end{array} .\right.
$$

The optimal solution is $\lambda^{*}, S^{*-}, S^{*+}, \theta^{*}$, so we can get the following conclusions:

1) If $\theta^{*}=1, \mathrm{DMU}_{\mathrm{j} 0}$ is a weak DEA efficiency (overall);

2) If $\theta^{*}=1$ and $S^{*^{-}}=0, S^{*+}=0, \mathrm{DMU}_{\mathrm{j} 0}$ is a DEA efficiency (overall);

3) If $\theta^{*}<1, \mathrm{DMU}_{\mathrm{j} 0}$ is a DEA invalid;

4) If there is a $\lambda_{j}^{*}(j=1,2, \cdots, m)$ in which holds $\sum_{j=1}^{n} \lambda_{j}=1$, then economies of scale of $\mathrm{DMU}_{\mathrm{i0}}$ remains same; If there is not a $\lambda_{i}^{*}(j=1,2, \cdots, m)$ in which holds $\sum_{j=1}^{n} \lambda_{j}=1$ and $\sum_{j=1}^{n} \lambda_{j}^{*}<0$, then economies of scale of $\mathrm{DMU}_{\mathrm{j} 0}$ remains increasing; If there is not a $\lambda_{j}^{*} \quad(j=1,2, \cdots, m)$ in which holds $\sum_{j=1}^{n} \lambda_{j}=1$ and $\sum_{j=1}^{n} \lambda_{j}^{*}>1$, then economies of scale of $\mathrm{DMU}_{\mathrm{j} 0}$ remains decreasing.

\subsection{Empirical Analysis on the New and the Old Circulation Modes of Agricultural Products of Fruits and Vegetables}

Beijing is a metropolis of China's fruit and vegetable consumption of agricultural products, so it has a frequently circulation of agricultural products, fruits and vegetables, empirical to the new and the old circulation modes of agricultural products of Beijing as the object, with various circulation patterns representative of the participants, including supermarkets, enterprises, wholesale markets, farmers market.

We get the initial investment and the final output of each link in the old and new circulation mode, according to the fruit and vegetable agricultural products related information access and empirical research, collection and processing of various data. The following data mainly come from the statistical yearbook and the field research.

\subsubsection{Input Indicators}

1) Material and service costs $x_{1}$ (yuan), including direct and indirect two parts.

2) Labor cost $x_{2}$ (yuan), including the discount on their own labor and the wages paid 
to others.

3) Land cost $x_{3}$ (yuan), including their own land rent and other collective land rent.

4) Logistics and transportation time costs $x_{4}$ (ten thousand yuan).

\subsubsection{Output Indicators}

1) The main finished product $x_{5}(\mathrm{~kg})$.

2) Net profit $x_{6}$ (yuan). The formula of net profit: net profit $=$ total profit $\mathrm{x}$ (1-Tax rate).

3) Cost margin $x_{7}(\%)$. Profit margin is the ratio of the surplus value to the total advance capital.

4) The average selling price for each $50 \mathrm{~kg} \mathrm{x}_{8}$.

\subsubsection{Empirical Analysis Based on DEA Model}

It chooses Beijing as the object of empirical study and selects representative supermarkets, enterprises, wholesale markets, farmers market and etc as the respondents.

1) In the wholesale market as the dominant circulation mode. Beijing Xinfadi wholesale market is DMU1, Beijing Yuegezhuang wholesale market is DMU2, Beijing Eight Mile Bridge wholesale market is DMU3.

2) "Farmer-Supermarket Direct-Purchase" as circulation mode. Carrefour supermarket is DMU4, Wal-Mart is DMU5, Hualian Supermarket is DMU6.

3) Logistics center as the main circulation mode. CMST is DMU7, Zhongdu logistics company is DMU8.

4) Leading enterprises as the dominant circulation mode. Tianan agriculture is DMU9, Material group is DMU10.

5) The circulation mode of agricultural products from the perspective of the whole industry chain. Eggplant Planting Farmers are DMU11. Survey data obtained are shown in Table 2.

The results of DEA evaluation are in Table 3.

Table 2. To show the sample data of five circulation modes.

\begin{tabular}{|c|c|c|c|c|c|c|c|c|c|c|}
\hline \multirow{12}{*}{$\begin{array}{c}\text { The } \\
\text { sample } \\
\text { data }\end{array}$} & Modes & $\mathrm{DMU}$ & $\mathbf{x}_{1}$ & $\mathbf{x}_{2}$ & $\mathbf{x}_{3}$ & $\mathbf{x}_{4}$ & $x_{5}$ & $x_{6}$ & $\mathbf{x}_{7}$ & $\mathrm{x}_{8}$ \\
\hline & \multirow{3}{*}{$\begin{array}{c}\text { Wholesale } \\
\text { market oriented } \\
\text { mode }\end{array}$} & DMU1 & 312 & 227 & 133 & 5567 & 256 & 192 & 0.32 & 103 \\
\hline & & DMU2 & 345 & 240 & 135 & 6257 & 292 & 219 & 0.36 & 118 \\
\hline & & DMU3 & 304 & 216 & 125 & 5289 & 236 & 184 & 0.31 & 101 \\
\hline & \multirow{3}{*}{$\begin{array}{l}\text { Supermarket } \\
\text { as core }\end{array}$} & DMU4 & 380 & 380 & 122 & 9876 & 260 & 242 & 0.33 & 120 \\
\hline & & DMU5 & 375 & 433 & 143 & 12,246 & 320 & 271 & 0.32 & 123 \\
\hline & & DMU6 & 371 & 367 & 117 & 9234 & 240 & 234 & 0.32 & 117 \\
\hline & \multirow{2}{*}{$\begin{array}{l}\text { Logistics centre } \\
\text { as main body }\end{array}$} & DMU7 & 358 & 283 & 149 & 4608 & 270 & 227 & 0.33 & 115 \\
\hline & & DMU8 & 403 & 325 & 167 & 4673 & 279 & 253 & 0.36 & 147 \\
\hline & \multirow{2}{*}{$\begin{array}{l}\text { Leading } \\
\text { enterprise as core }\end{array}$} & DMU9 & 398 & 372 & 166 & 8016 & 280 & 250 & 0.31 & 120 \\
\hline & & DMU10 & 408 & 458 & 170 & 8208 & 301 & 273 & 0.32 & 121 \\
\hline & The new mode & DMU11 & 239 & 195 & 158 & 2045 & 225 & 163 & 0.24 & 78 \\
\hline
\end{tabular}


Table 3. To show the results of DEA evaluation.

\begin{tabular}{|c|c|c|c|c|c|c|c|c|c|c|c|}
\hline \multirow{8}{*}{$\begin{array}{c}\text { The results } \\
\text { of DEA } \\
\text { evaluation }\end{array}$} & Modes & Sample & $\theta$ & $S_{1-}$ & $S_{2-}$ & $\mathrm{S}_{3-}$ & $S_{4-}$ & $S_{5+}$ & $S_{6+}$ & $\mathrm{S}_{7+}$ & $S_{8+}$ \\
\hline & Wholesale market & DMU2 & 0.8 & 28.6 & 0 & 18.4 & 278 & 5.5 & 0 & 19.8 & 0 \\
\hline & & DMU4 & 1 & 0 & 0 & 0 & 0 & 0 & 0 & 0 & 0 \\
\hline & $\begin{array}{l}\text { Supermarket } \\
\text { as core }\end{array}$ & DMU5 & 0.9 & 13.2 & 0 & 0 & 102.5 & 0 & 0 & 0 & 0.09 \\
\hline & Logistics centre as main & DMU7 & 0.9 & 0 & 17.8 & 0 & 151 & 0 & 0 & 0 & 0 \\
\hline & body & DMU8 & 0.8 & 20.1 & 0 & 11.7 & 0 & 0 & 28.3 & 0 & 0.1 \\
\hline & Leading enterprise & DMU9 & 0.8 & 24.2 & 6.7 & 0 & 260 & 0 & 17.6 & 0 & 0 \\
\hline & as core & DMU10 & 0.8 & 28.2 & 0 & 18.7 & 284 & 5.6 & 0 & 19.4 & 0 \\
\hline
\end{tabular}

The determination theorem of the solution of the DEA model can be known: If $\theta=1$ and $S^{*-}=S^{*+}=0, D M U j 0$ is the overall effective DEA. Table 3 shows that DMU4 and DMU11 are the overall effective DEA in 11 DMUs, others are invalid DMUs. So the output and input of DMU4 and DMU11 will reach the maximum value.

From the output of the $\theta$ value can be seen five circulation modes of the highest efficiency is the circulation mode of the fruits and vegetables from the perspective of the whole industry chain.

\section{Summary}

From above contents, we can get that the efficiency of circulation mode of agricultural products of fruits and vegetables from the perspective of the whole industry chain is highest. That is the new circulation model which is more efficient than the old one. Thus, the new circulation model can make up for the deficiency of the circulation efficiency of the old mode and it can promote the circulation efficiency of agricultural products of fruits and vegetables in Beijing.

But there are still some limitations about the circulation mode of agricultural products from the perspective of the whole industry chain.

Under the model system, the workload of the core enterprise is huge, including production management of agricultural products, agricultural raw materials and agricultural procurement, agricultural product technical advice and guidance, monitoring the quality of agricultural products, detection, agricultural products sales channels and so on, so the strength of the core enterprises will be very high.

The mode has the certain risk, such as: the risks of obtaining orders, the risk of agricultural purchasing and the risk of agricultural products cannot be shipped out promptly, etc.

In short, if you want to change the present situation of Beijing's logistics, you should stabilize prices of agricultural products, guarantee the quality and safety of agricultural products, improve the efficiency of logistics, and reduce logistics cost. And it must be 
guided by the idea of industrial chain to encourage the participants in the industry chain to coordinate and cooperate and complement each other. At the same time, the government should introduce corresponding policies and regulations, provide corresponding financial subsidies and regulate the circulation order of agricultural products by macro-control means. In addition, there will be a worthy research area to create a model of agricultural product logistics with Chinese characteristics, that is how to combine the successful experience of foreign countries and the actual situation of our country [8].

\section{References}

[1] Li, L. (2011) Study on Circulation Pattern and Efficiency of Fresh Agricultural Products. Ph.D. Thesis, Ocean University of China.

[2] Tu, H.B. (2013) A Empirical Research on Agricultural Products Circulation Modernization in China. Ph.D. Thesis, Central China Agricultural University.

[3] Zhu, H.Y. and Xie, E.Q. (2013) Study on Regional Agricultural Products Circulation Mode. Issues in Agricultural Economy, No. 10, 63-68.

[4] Wang, B. (2008) Empirical Research on the Circulation Pattern and Circulation Efficiency of Fresh. Ph.D. Thesis, Jiangnan University.

[5] Zhou, H.L. (2010) Research on the Mode of Agricultural Products Circulation Based on Modern Logistics. The South of China Today, No. 4, 88-91.

[6] Gong, M. and Qi, C.J. (2012) Restriction Factor and Breakthrough Point of Agricultural Products Circulation Efficiency in China. China Business and Market, No. 11, 43-48.

[7] Zhou, J.G. and Shang, J. (2015) Study on the Evaluation of Agricultural Products Circulation Efficiency Based on Different Circulation Patterns. Journal of Anhui Agricultural Sciences, No. 2, 317-321.

[8] Li, L.Y. and Li, C.G. (2012) The Main Problems and Countermeasures of the Circulation Modernization of Agricultural Products with Chinese Characteristics. China Business and Market, No. 2, 21-26.

Submit or recommend next manuscript to SCIRP and we will provide best service for you:

Accepting pre-submission inquiries through Email, Facebook, LinkedIn, Twitter, etc.

A wide selection of journals (inclusive of 9 subjects, more than 200 journals)

Providing 24-hour high-quality service

User-friendly online submission system

Fair and swift peer-review system

Efficient typesetting and proofreading procedure

Display of the result of downloads and visits, as well as the number of cited articles

Maximum dissemination of your research work

Submit your manuscript at: http://papersubmission.scirp.org/ 